\title{
Hqrizons $\lambda$
}

\section{Programming For HIV PREVENTION IN SOUTH African SCHOOLS}

s national education programs incorporate H IV prevention into school curricula, policymakers and educators need to know what they can expect from these initiatives. $C$ an such courses influence the behavior of students as well as their knowledge and attitudes? If not, what can these courses reasonably be expected to accomplish, and what part can they play in overall HIV programming for youth?

To help answer these questions, the

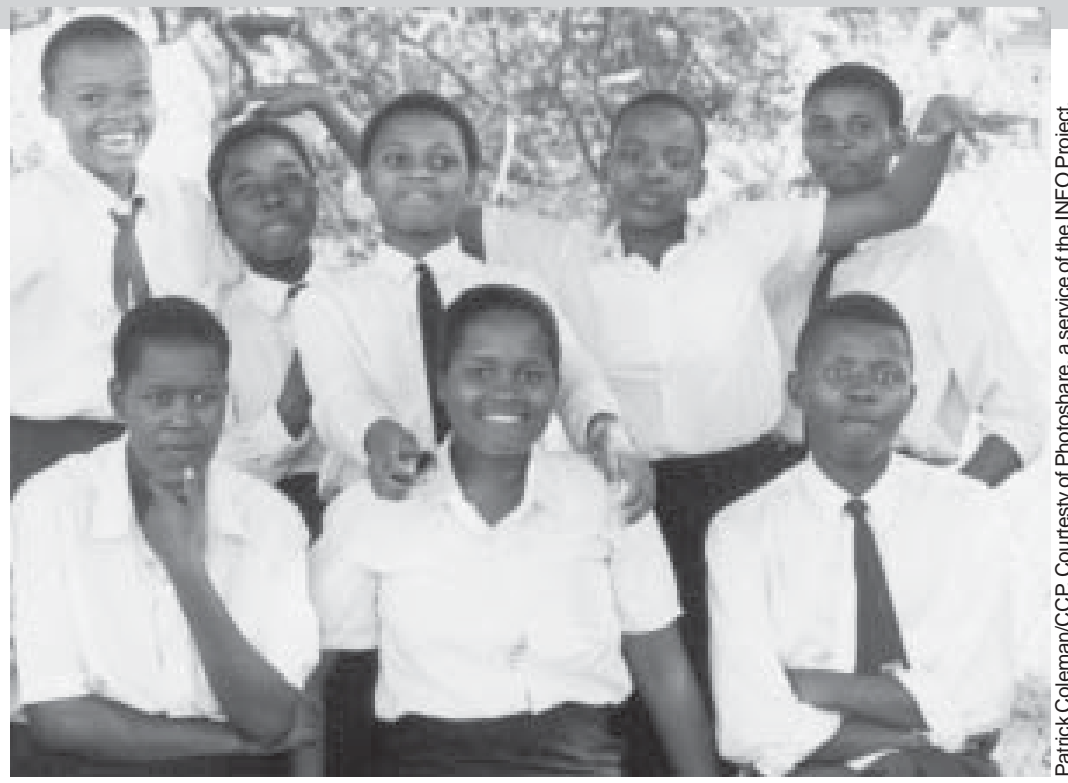
$M$ edical Research Council of South Africa and the $\mathrm{H}$ orizons Program studied the Life Skills Grade 9 Curriculum, a school-based HIV/ AIDS initiative, as it was introduced in the Pietermaritzburg region of KwaZulu N atal Province in 2001. The 16hour Grade 9 Curriculum is taught at least once a week over two school terms as part of the subject, Life $O$ rientation. The national and provincial South African departments of education, health, and social welfare collaborated on the curriculum design, teacher training, and course introduction.

$\mathrm{H}$ orizons assessed the life skills program in KwaZulu Natal using both a population based survey ${ }^{1}$ and an evaluation of the course curriculum. This report focuses on the impact of the curriculum that was being introduced to ninth grade students.

${ }^{1}$ See M agnani, B. et al. 2003. "The I mpact of Life Skills Education on Adolescent Sexual Risk Behaviors," H orizons Research Summary. Washington, D.C.: Population Council.

\section{Study Methods}

The study used a quasi-experimental research design that included surveying teachers and students. D ata were collected from students in grade 9 in the Pietermaritzburg region of $\mathrm{K}$ waZulu $\mathrm{N}$ atal Province. Twenty-two schools participated: 11 of the schools in which the course was first introduced served as intervention schools, and 11 where the course had not been taught served as control schools. Two classrooms within each school were randomly selected to participate in the study. To measure the effectiveness of the program among students, a pre-test/ multiple post-test control group design was used. Students completed the surveys at baseline (T1), immediately after the course was finished (T2), and four months later (T3).

Researchers used statistical tests to determine changes occurring in the control and intervention groups across the rounds of data collection. 


\section{Study Subjects}

In total, 1,141 students participated in the study, but for the indicators presented here, only the 646 students who participated in all three rounds of data collection were included in the analysis. These students were demographically representative of the total number of students in the study. The mean age was 15.8 years (range: 12 to 21 years). There was an almost equal distribution of male and female students, and the majority spoke Zulu as their primary language.

Pre- and post-intervention surveys were carried out with teachers to assess changes in their H IV knowledge and attitudes as well their perceived ability to teach the material. Eleven teachers from the intervention schools (five male and six female) participated in a five-day training course, of whom nine had had some experience teaching a life skills curriculum.

\section{Key Findings}

The program did not increase sexual activity. At baseline, approximately 30 percent of students

\section{Department of Education's Grade 9 Curriculum Content}

\section{HIV/AIDS Facts}

- Modes of transmission, immune system, disease progression

- Understanding my body and keeping it safe and healthy

Life Skills Focused on HIV

- Self-esteem and self-awareness

- Family, peer group, and community relationships

- Attitudes and values

- Sex and sexuality (includes abstinence, reduction in partners, and condom use)

- Rape and abuse

- Decision making, conflict resolution, and assertiveness

- Basic counseling skills, care, and support

- Substance abuse
Approval of teenage abstinence increased within the intervention group, particularly among males. The study measured students' attitudes about abstinence in two ways. First, they were asked whether it was $\mathrm{OK}$ for teenagers to not have sex. At baseline, 54 percent of the males in the experimental group agreed with the statement, while at $\mathrm{T} 2$, this figure increased to 81 percent $(p<.001)$. At T 3 the proportion decreased slightly to 73 percent, but was still significantly greater compared to T1 $(p<.001)$. No similar trend was detected among males in the control group or among females in either group. 
Figure 1 Students who think it's a good idea not to have sex while a teenager

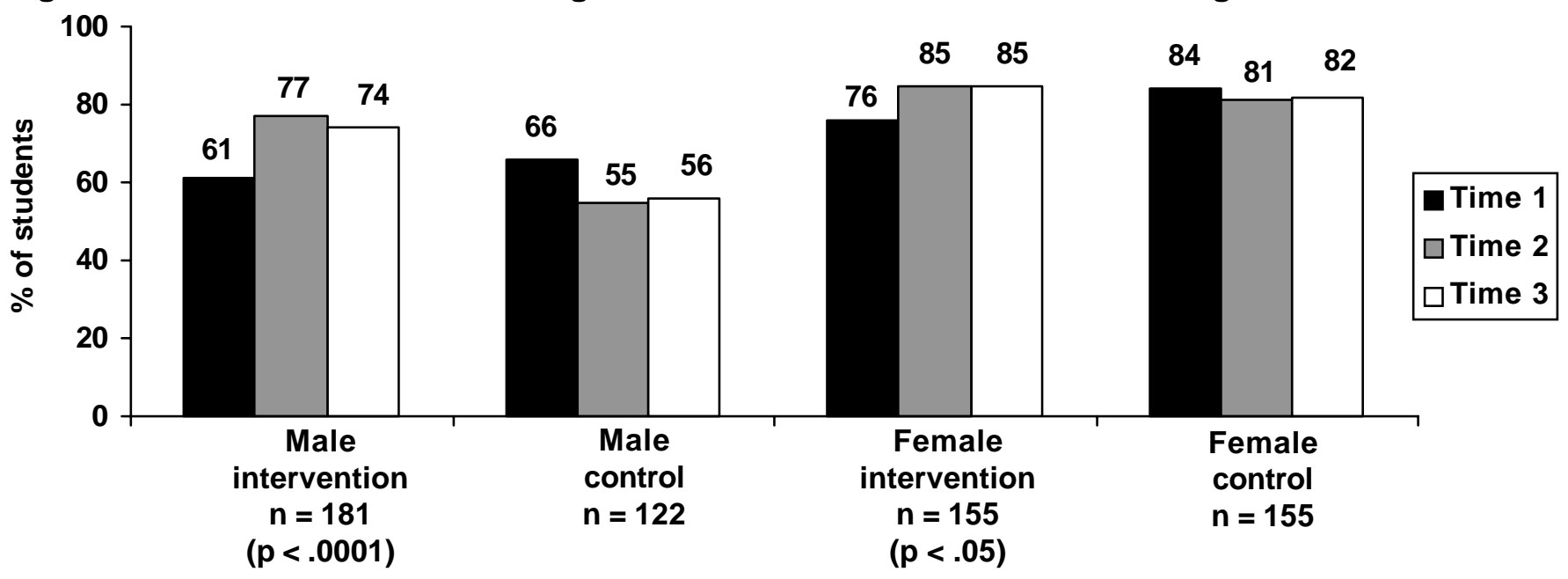

Students were also asked if they believed that it is a good idea not to have sex while a teenager. As shown in Figure 1, 61 percent of intervention males and 76 percent of intervention females supported abstinence among teenagers at baseline. For both groups there was a statistically significant increase in the proportion that agreed with the statement at T 2 (males: $p<.001$; females: $p<.05$ ), and this was maintained for both groups at T3. I n contrast, support for abstinence among the control group was less at $\mathrm{T} 2$ and $\mathrm{T} 3$ compared to T 1.

\section{M ost students intended to either abstain or} use a condom, but the program did not result in increased condom use. Students were asked about their intention to engage in sexual activity over the next three months. At baseline, approximately 69 percent of students in both the control and intervention groups intended to not have sex, and they maintained this intention at $\mathrm{T} 2$ and T3. The figures were similar for males and females.

An additional one-quarter of students in the intervention group and the control group claimed that they intended to have sex with a condom. At T2, this percentage increased to 33 percent among the intervention group but decreased to 23 percent among the control group $(p<.01)$. Intention to use a condom within the intervention group was maintained at a slightly lower level at T3 (30 percent). Although there was a statistically significant increase in intention to use condoms within the intervention group, there was no evidence that actual condom use had increased among males or females.

\section{M ore males in the intervention group} reduced their number of sexual partners. At baseline, the vast majority of sexually experienced students reported no partner or just one partner in the previous six months, and this remained true at T2 and T3. Researchers then examined the change in partners over time. For example, among male students reporting more than one partner at $\mathrm{T} 1$, a greater proportion in the intervention group said they were monogamous at $\mathrm{T} 2$ compared to males in the control group ( $27 \mathrm{vs.}$ 21 percent). Similarly, the proportion of intervention males who reported being monogamous at $\mathrm{T} 1$ but said they had more than one partner at T 2 was less than the proportion of control males who reported this ( 7 vs. 25 percent). Although these differences are not statistically significant, they suggest a trend among intervention males toward maintaining or switching to monogamy. Few females had multiple partners in either the intervention or control group.

\section{M ost students did not support sexual coercion at baseline, and there was little change after the course. Students were asked whether they agreed with certain statements related to gender roles in relationships, such as "It is $\mathrm{OK}$ for a boyfriend to force his girlfriend to have sex." D espite high levels of partner violence in South Africa, it was encouraging to find that at}


each data collection round, the vast majority of males and females in both the intervention and control groups did not support sexual coercion by boyfriends. For example, at baseline 80 percent of males in the intervention group did not agree with the statement, and at T 3 this figure had increased to 87 percent.

\section{Students would like the course to better address peer pressure and practical communication skills. At baseline, about a third} of males in the control (35 percent) and intervention (30 percent) groups agreed with the statement, " $\mathrm{M}$ y friends encourage me to have sex," while only 13 and 15 percent of females in each group, respectively, felt this way. Among males in both groups, the proportion that agreed with the statement increased slightly over time, while for females, there was a decrease in the proportion of females who agreed with this statement.

D espite differences in experience, after the course, nearly half of both male and female students expressed some level of doubt in their ability to resist peer pressure from friends to engage in sexual activity. At least 60 percent of students indicated they would benefit from learning the necessary skills to resist pressure from friends and to help them talk to their parents and partners about HIV/ AIDS.

\section{Teachers enjoyed teaching life skills yet tended to focus on factual information.}

Teachers found teaching the course to be rewarding, especially when students opened up, relaxed, and were willing to participate in class discussion. H owever, teachers reported focusing on factual aspects of the curriculum rather than on the life skills aspects. For example, four of the eleven teachers did not address the coping skills section of the curriculum, which included such topics as decision making, assertiveness, and communication, while all of the teachers said they covered factual information on HIV/ AIDS.

\section{Conclusion and Next Steps}

The Life Skills School Curriculum had a positive impact on students' knowledge of HIV/ AIDS, attitudes about abstinence, and intention to use condoms. These effects are important for laying the groundwork for behavior change. There was, however, no evidence of increased adoption of such protective behaviors as abstinence and condom use. This may be because the teachers did not focus as strongly on the life skills components as on the factual HIV/ AIDS information. $M$ oreover, this was the first time that the teachers had taught this particular curriculum. Their skills, comfort level, and effectiveness are likely to improve with experience.

To strengthen the course to foster behavior change, more attention should be placed on helping teachers cover the life skills components and on responding to students' desire for greater emphasis on resisting peer pressure and for talking to parents and partners about sex.

\section{All schools in South Africa now teach this curriculum to students in grade 9. In M ay 2003, the researchers discussed the findings with key stakeholders at a symposium in D urban. The findings are currently being used by the D epartment of Education of KwaZulu $\mathrm{N}$ atal to refine the program. In addition, the findings will be distributed to the full-time HIV/ AIDS program coordinators in each province, who manage the training, revisions, monitoring, and evaluation of the Life Skills Programme.}

D ecember 2003

The principal investigators are Priscilla R eddy and Shegs J ames of the M edical Research Council-Cape Town, and Ann $M$ cC auley of H orizons/ ICRW. For more information on this study, please contact Shegs ames (shegs.james@mrc.ac.za) or Ann M cCauley (amccauley@ocdc.org). J essica Greene of Horizons/ Population Council compiled this summary.

Suggested citation: Reddy, P. et al. 2003. "Programming for H IV Prevention in South African Schools," Horizons Research Summary. Washington, D.C.: Population Council.

\section{Hgrizons}

Population Council/ Horizons

Communications Unit

4301 Connecticut Avenue, NW

Suite 280

Washington, DC 20008
Population Council

Tel: $202-237-9400$

Fax: 202-237-8410

horizons@pcdc.org

www. popcouncil.org/ horizons
Usaw This publication was made possible through support provided by the Global Bureau of Health/HIV-AIDS, U.S. Ant走走 Agency for International Development, under the terms of Award No. HRN-A-00-97-00012-00. The opinions expressed herein are those of the authors and do not necessarily reflect the views of the U.S. Agency for International Development. 